Revista Iberoamericana. Vol. LXIV, Núms. 184-185, Julio-Diciembre 1998; 471-483

\title{
ARTES DE LA LECTURA EN LA CIUDAD DEL ÁGUILA NEGRA: LA LECTURA EN VOZ ALTA Y LA RECITACIÓN EN SANTAFÉ DE BOGOTÁ A FINES DEL SIGLO XIX
}

POR

\section{J. Eduardo Jaramillo-Zuluaga Denison University}

La historia que quiero contar en esta ocasión es una historia feliz; es la descripción de esa época paradisiaca en que llamaban a Santafé de Bogotá "La ciudad del águila negra", un epíteto que nunca llegó a ser popular y que aparece aquí o allá, en algunas páginas de fines del siglo XIX o de comienzos del XX. ${ }^{1}$ En esa época, cuando Colombia se preparaba para conmemorar el centenario de su independencia de España, Bogotá superaba apenas los 110.000 habitantes, analfabetos en su inmensa mayoría. ${ }^{2}$ Atribuirle el título de "ciudad del águila negra" no podía resultar entonces más inapropiado. Descontada la vaguedad del epíteto o sus connotaciones siniestras, pocos, muy pocos, relacionarían el águila negra con el escudo de armas que Carlos V le había conferido a la ciudad en 1548 y que mostraba un águila rampante en campo de oro y orlada de granadas entreabiertas. Y sin embargo, los escritores que así llamaban a Bogotá no podían ocultar la felicidad de haber hecho un hallazgo inmortal o, quizás más exactamente, puesto que escribían para unos pocos, de haber encontrado una expresión que les otorgaba el beneplácito y la complicidad de algunos cuantos lectores privilegiados.

Otro epíteto, el que declaraba a Bogotá “Atenas suramericana”, alcanzó en cambio una mayor difusión aunque su visión estilizada de la ciudad no resistía tampoco el menor examen. Si en la actualidad poco tiene que ver la imagen clásica de Atenas con la de una Bogotá moderna, abigarrada y que escritores como Luis Fayad describen sin compasión

\footnotetext{
${ }^{1}$ La presente investigación hubiese sido imposible sin el generoso apoyo del Denison University Research Fund, al que expreso aquí mi agradecimiento. A propósito de la ciudad del águila negra, resulta innegable el candor de una nota bio-bibliográfica sobre Soledad Acosta de Samper, escrita a mediados de 1909: "Volvió a Bogotá y sólo dos años después de la muerte de su esposo, acaecida en 1888, dejó de nuevo la ciudad del águila negra" (446). Además de sus epítetos, la capital de Colombia ha tenido diversos nombres. La Constitución de Angostura (1819) reemplazó el de "Santa Fe" por el de "Bogotá"; la Constitución de 1991 substituyó el de "Bogotá" por el de "Santa Fe de Bogotá". En el lenguaje hablado, sin embargo, se continúa llamando a la ciudad "Bogotá", en el escrito parece dominar la grafía de "Santafé de Bogotá" sobre la de "Santa Fe de Bogotá".

${ }^{2}$ El censo de 1905 registra 100.000 habitantes en Bogotá; el de 1912, 121.257 y una tasa de crecimiento del $2.8 \%$, lo que permite calcular la población de 1909 en algo más de 110.000 habitantes (Gilbert 89). De acuerdo con el censo de 1912, el 80\% de la población era analfabeta (Silva Olarte 62). Sobre las precarias condiciones de la educación en el primer tercio del siglo XX, puede consultarse Helg 35 ss.
} 
como una ciudad caótica y sucia en la que alternan restaurantes y puestos de fritanga y por cuyas calles transitan gamines, funcionarios, carteristas, timadores, detectives, prostitutas, pregoneros, culebreros y vendedores ambulantes (Fayad 122), en el pasado esta imagen no fue muy diferente aunque sus aristas más cortantes se hayan limado en las memorias que han llegado hasta nosotros. Con pocas excepciones, grabados, acuarelas y cuadros de costumbres atribuyen a la ciudad una atmósfera mansa, casi idílica, en la que transcurría la vida de aguadoras y reclutas, beatas y albañiles, músicos y chicharroneros, vergonzantes y locos legendarios y divertidos que nada sabían de águilas ni de Atenas (Francisco de Paula Carrasquilla). Si la "Ciudad del Águila Negra" o la "Atenas suramericana" designaban alguna realidad, debía tratarse entonces de una realidad cercada, limitada, una superficie de adoquines bien puestos, a cinco o seis gradas sobre el nivel de la calle y del mundo, en la que podían verse algunos cuantos bogotanos instruídos, los "doctores", paseándose en las mañanas soleadas o en las tardes, poco después de la cena. Esos notables habitantes llamaron a aquel lugar "el altozano", un cultismo que deriva del latín"ante-", "elevación", y "ostium", "puerta de entrada". No otra cosa fue pues la "Atenas suramericana": el atrio de la catedral, en la Plaza de Bolívar, y ciertas reglas de cortesía y también un hábito de conversaciones ceremoniosas y elevadas.

Sin mayores referencias suele decirse que Bogotá fue bautizada "Atenas suramericana" por el naturalista alemán Alexander von Humboldt y también por el viajero francés Eliseé Reclús o el diplomático chileno Miguel Cané. En el volumen XVIII de su Nouvelle geographie universelle (1876-1894), después traducido con el título de Colombia, Reclús hace una descripción de Bogotá en la que destaca la biblioteca de la ciudad, su observatorio, su instituto de bellas artes y sus paseos arbolados (180). Cané, por su parte, en las Notas de viaje sobre Venezuela y Colombia (1882), elogia la atmósfera culta que se respira en el altozano, la oportunidad que ofrece de entablar relación con hombres de talento dedicados a la política, las armas y las letras, y compara el altozano a "una bolsa, un círculo literario, un areópago, una coterie, un salón de solterones, una coulise de teatro, un forum" (153). La generosidad de estos extranjeros, sin embargo, tiene límites: ni Reclús ni Cané llegan a usar la expresión “Atenas suramericana” y, en consecuencia, la invención del epíteto bien puede atribuirse a la euforia nativa, a las numerosas anécdotas caballerescas que registran autores de fines del siglo XIX como Laureano García Ortiz, José Joaquín Casas o Ismael Enrique Arciniegas.

Casas, para dar un ejemplo, recuerda las circunstancias en que se difundió el poema " $\mathrm{La}$ luna" de Diego Fallon (1882). Llevaba Fallon, dice, varios meses componiendo el poema cuando le leyó algunas estrofas a su amigo Posse Martínez. Posse Martínez quiso publicarlo en un periódico apenas estuviera terminado pero Fallon prefirió escuchar antes la opinión de Ricardo Carrasquilla, su consejero en asuntos literarios. Unos días más tarde le enseñó el poema a su amigo y Carrasquilla, al verlo, le pidió el manuscrito con la excusa de leérselo a su familia. Esa misma noche Carrasquilla reunió a los escritores de El Mosaico, y sin que Fallon se enterara, decidieron imprimir el poema en hojas sueltas y distribuirlo de inmediato por toda la ciudad. ${ }^{3}$ A la mañana siguiente, mientras transitaba por sus calles habituales,

${ }^{3}$ El Mosaico es una de las publicaciones periódicas más importantes de Colombia en el siglo XIX. Apareció, con diversas interrupciones, entre 1858 y 1872 . En torno suyo se reunieron autores de 
el sorprendido Fallon recibía felicitaciones de todas partes. Y aún no había terminado el día cuando ya uno de los mejores declamadores de la ciudad, José María Rojas Garrido, lo había memorizado y recitaba las veintiocho estrofas del poema sobre las mesas de La Botella de Oro:

\author{
Ya del oriente en el confín profundo \\ La luna aparta el nebuloso velo, \\ $Y$ leve sienta en el dormido mundo \\ Su casto pie con virginal recelo. \\ Absorta, allí la inmensidad saluda \\ Su faz humilde al cielo levantada; \\ Y el hondo azul, con elocuencia muda, \\ Orbes sin fin ofrece a su mirada ...
}

Al llegar a este punto en sus recuerdos, Casas pierde toda noción de mesura. Aun si aceptamos el hecho de que el poema fuera considerado en la época como "un verdadero acontecimiento literario", resulta delirante imaginar que en una Bogotá como la de entonces, más rudimentaria que idílica, más inculta que clásica, "todos leían, todos aprendían de memoria, todos recitaban 'La luna"”. "Decidme, señores - concluye Casas-, si tiene poca sal y pimienta la historia anecdótica de Bogotá, y si Bogotá merece o no merece el título de Atenas de Suramérica" (194). La moraleja de la historia, sin embargo, tiene menos que ver con la fama del poema "La luna" que con la camaradería que existía al interior de un grupo. Gracias a esa camaradería, una noche Carrasquilla puede convocar de improviso a los contertulios de El Mosaico, leerles en voz alta un poema, publicar esa misma noche el poema, salir a la calle a buscar lectores insomnes que lo lean y escuchar al día siguiente la declamación de sus versos en una taberna de Bogotá. Hemos dicho que la "Atenas suramericana" tenía por escenario ritual los escasos metros cuadrados del altozano; agreguemos ahora que su sentido hiperbólico se originaba en la misma camaradería con que los habituales del altozano se trataban, en la homogeneidad que se imponían y que unos guardaban o vigilaban en otros. Sólo al interior de un círculo tan exclusivo y estrecho podía imaginarse que se vivía en una utopía letrada, en una ciudad ideal cuyos habitantes declamaban al unísono un centenar de versos dedicados a la luna.

Durante muchos años aquellos "espíritus selectos", como a sí mismos se llamaban, lograron conservar su sueño intacto. Discurriendo sobre el altozano, contemplaban el ir y venir de otros seres humanos muy distintos a ellos, pobres, ignorantes, que desfilaban a sus pies y con quienes compartían un país. No negaban su existencia. Los mencionaban en sus obras literarias, en sus poemas y sus cuadros de costumbres, transformándolos en seres dóciles y limpios, "higiénicos" en palabras de Ángel Rama (91). Obligados a convivir con ellos, parece casi un acto de heroísmo el decoro con que lograron mantenerlos a raya, la discreción con que evitaron referirse a cualquier tipo de confrontación con ellos. Por ese 
motivo, resulta excepcional la humillación que José María Samper recibió un día de 1846. Estando en el altozano con unos amigos, vio a un hombre que pasaba por la calle golpeando a su mujer. Samper, movido por un impulso caballeresco, bajó de un salto las gradas del atrio dispuesto a intervenir. Atacó al hombre pero, contra lo que esperaba, la mujer - la "guaricha" - comenzó a insultarlo llamándolo "cachaco, pati-aforrado, entremetido" y gritándole que su marido era libre de golpearla cuanto quisiera (188). Igualmente excepcional, aunque más gloriosa, es la contienda que protagonizó Luis María Mora, uno de los poetas de la Gruta simbólica. ${ }^{4}$ Hallándose con sus amigos en un establecimiento en el que servían meriendas o "piquetes", se vio comprometido a jugar una partida de tejo con unos desconocidos, unos "guaches", unos "destacadísimos profesionales indígenas del juego popular". Ante la admiración de todos, Mora, a quien sus amigos llamaban "Moratín", aceptó el reto de inmediato; tomó el disco con maestría y, dando los escupitazos y los pequeños saltos rituales antes de lanzarlo, reventó la mecha y ganó la partida de un solo golpe. Y cuando aún no habían salido de su asombro los guaches, Moratín se volvió hacia ellos mirándolos despectivamente y les dijo con aire provocador: ‘Y también sé griego!"” ("Don Luis María Mora" 19). Es difícil imaginar la escena que vino a continuación; la anécdota termina en el momento sublime en que Mora, como lo había hecho Samper con menos suerte, da muestras de su naturaleza distinguida, de su condición superior de "cachaco", de su dominio sobre los códigos de comportamiento y expresión de los otros, los "guaches".

Como suele ocurrir con los espejismos, el de la "Atenas suramericana" es un espejismo feliz, el sueño, diariamente vivido en el atrio de la catedral, de pertenecer a una colectividad homogénea y de articular, desde su interior, un programa civilizador que se impusiera sobre los otros, los guaches, los bárbaros que ignoraban el griego y pasaban por alto las más elementales reglas de cortesía. La sangrienta historia política y social de Colombia registra los diversos matices de ese programa, desde la idealización de los "guaches" en cuadros de costumbres hasta su colonización o su exterminio. ${ }^{5}$ Esa historia también da cuenta, por otra parte, de las funestas divisiones que en ocasiones desbandaron a los privilegiados del altozano y los volvieron a unos contra otros; por encima de esas divisiones, sin embargo, dos hechos incontrovertibles mantuvieron siempre su homogeneidad: el espíritu caballeresco y el lenguaje esmerado que empleaban lo mismo en tiempos de paz que en tiempos de guerra. Sólo por esta causa resulta comprensible, y también asombroso, que los primeros indicios de la disolución de la "ciudad del águila negra" o de la "Atenas suramericana" tuvieran menos que ver con la censura, el destierro o las guerras civiles colombianas, que con una discusión inocente: la polémica que en 1891 se desató en los diarios bogotanos en torno a la fundación de un ateneo para la ciudad. ${ }^{6}$

El 19 de agosto de 1891, el periódico El Correo Nacional publicó un artículo firmado por un tal "Academo" que lamentaba la pobreza cultural de Bogotá y urgía a los intelectuales

\footnotetext{
${ }^{4}$ Con el nombre de La Gruta Simbólica se conoce una asociación de más de setenta poetas bogotanos de fines del siglo XIX, románticos en su inmensa mayoría, y más conocidos por sus anécdotas que por su obra poética. Los más recordados son Julio Flórez (1867-1923), Clímaco Soto Borda (1870-1919), Maximiliano Grillo (1868-1949), Víctor M. Londoño (1870-1936) y Luis María Mora (1869-1936).

${ }^{5}$ Sobre el programa civilizador de los "cachacos", véase Palacios.

${ }^{6}$ Una reseña de esta polémica puede seguirse también en Santos Molano (710 ss).
} 
a participar de manera más activa en "el mercado intelectual del mundo" y a fundar un "foco de luz", un “Ateneo de Bogotá" (3). Baldomero Sanín Cano rechazó la idea. En un artículo sin firma publicado en El Telegrama del 28 de agosto, hacía referencia a las intervenciones de otros dos escritores en la polémica, "Macabeo" y "Ateniense". De acuerdo con Sanín Cano, "Macabeo" se esforzaba por demostrar la existencia de la vida cultural bogotana haciendo "una lista de obras que no llegan a veinte, y que han visto la luz en los últimos tres años" y "Ateniense", por su parte, hablaba con nostalgia de un ateneo que había existido en el pasado y del que, en realidad, además de las sillas y las mesas, no quedaba sino "un discurso bellísimo de don Santiago Pérez, escrito en fabla clásica, sin mancha, y otro del señor Camacho Roldán en que nos prueba con frases armoniosas y números redondos, que el mundo es todavía casi exclusivamente agricultor". Reconociendo, pues, el hecho de que la vida cultural de Bogotá no sólo era "rudimentaria, sino imperfecta" y de que no había profesores "porque nuestro Erario no puede pagarlos", Sanín Cano pasaba en seguida a cuestionar lo que el mismo "Academo" entendía por vida intelectual:

\begin{abstract}
Hay sin embargo en Bogotá una distinción que hacer en punto a la vida del alma, y es que hay dos muy distintas y muy fáciles de separar: la vida intelectual pública, en nuestro concepto nula; y la vida intelectual íntima con la cual nos ha favorecido la Providencia. No hay para qué venir a probar que falta la primera donde no hay conferencias, ni periódicos que remuevan y manoseen las ideas contemporáneas, ni cursos públicos, ni centros intelectuales de género alguno. La otra sí es muy generosa y sobre todo muy barata. En Bogotá hay decenas de espíritus cultivados con delicadeza, que llevan cuenta detallada de las elevaciones y depresiones de su yo y que siguen el movimiento de los espíritus en la Europa civilizada. Y lo que es más raro y más ventajoso para los bogotanos, el tratar a esta gente es cosa muy fácil y barata [...]. En Bogotá, yo, usted, el primer quisque, emparejamos con Vargas Vega, con Jorge Holguín, con J. Ignacio Escobar, con J. A. Silva o con Carlos Eduardo Coronado y echamos por esas calles a parlar de lo nuevo y de lo trascendental. Esto siquiera es una ventaja entre tan dolorosas miserias (5752).
\end{abstract}

Es curiosa esta resignada defensa de la camaradería del altozano en un escritor que, al parecer, siempre promovió la discusión y la secularización de las ideas. Sin duda, resultaba más fácil y barato, para quienes contaban con una educación y un traje aceptables, dirigirse al altozano y elegir un interlocutor generoso con quien ventilar ciertas opiniones, pero también era posible organizar una tertulia, fundar una sociedad literaria o publicar tres o cuatro cuartillas en los innumerables periódicos que en ese mismo año de 1891 circulaban por la ciudad, algunos de ellos tan respetables como El Repertorio Colombiano (18981899), El Telegrama (1886-1904), El Heraldo (1889-1899) o La Revista Ilustrada (18901894). ${ }^{7}$ Evidentemente, si Sanín Cano no admitía la existencia, así fuese rudimentaria, de una "vida intelectual pública", era porque la "vida intelectual privada", la camaradería del altozano, permeaba todos los ámbitos del quehacer intelectual bogotano. El recurso del

\footnotetext{
${ }^{7}$ Aunque la vida de las publicaciones periódicas era bastante incierta, ello no impedía su número ni su variedad. En 1891 circulaban en Bogotá medio centenar de diarios, periódicos y revistas de todo tipo, ocho de las cuales aparecieron por primera vez en ese mismo año: El Colombiano, El Constitucional, El Gladiador, La Legalidad, La Prensa, El Relieve, El Mago y la Literatura de "El Heraldo" (ver Biblioteca Nacional de Colombia).
} 
anonimato o de seudónimos como "Academo", “Ateneo"y "Macabeo", son un ejemplo del cuidado que se ponía en los periódicos para no herir susceptibilidades y conservar esa camaradería. En cualquier caso, en la baraja que llevaba de la intimidad de la "vida intelectual privada" a la precariedad de la "vida intelectual pública", existieron a fines del siglo XIX diversos medios, diversos géneros retóricos, diversas artes que determinaron la manera de leer, de discutir ideas, de comentar libros y, en una palabra, de hacer crítica literaria en Colombia.

La primera de esas artes fue el arte de la conversación. De este género bastará aquí con apuntar dos cosas. ${ }^{8}$ En primer lugar, que el conversador por excelencia era el cachaco y el mejor observador del cachaco fue el diplomático chileno Miguel Cané quien lo definía como un "calavera de buen tono, alegre, decidor, con entusiasmo comunicativo" (159). En una recepción que le ofrecieron en Bogotá y en la que tuvo oportunidad de alternar con muchos de los habituales del altozano, Cané advirtió en ellos

una viveza de inteligencia sorprendente, eléctrica en su rapidez de percepción [...]. El sprit chispea en la conversación; una mesa es un fuego de artificio consante; el chiste, la ocurrencia, la observación fina, la cuarteta improvisada, la décima escrita al dorso del menú, el aplastamiento de un tipo en una frase, la maravillosa facilidad de palabra [...] no tiene igual en ninguna otra agrupación americana (158).

En segundo lugar, vale la pena anotar que el modelo de conversación de los cachacos tenía un origen francés. Lo llamaban, muy a la francesa, L 'art de la causerie. Una vez, en una reunión, el poeta José Asunción Silva le describió a su amigo Hernando Villa cómo podía hacerse un buen causeur y le aconsejaba que

nunca [tratara] un tema hasta agotarlo, sino que intempestivamente [saltara] a otro y que así [tendría] pendientes a los oyentes, esperando qué nuevo asunto [trataría y de esa forma], con gracia inimitable, [debería contar] anécdotas, aparentemente insignificantes, y profundas en el fondo" (Villa 378).

Así pues, el éxito de la causerie residía en la habilidad del conversador para sumergir a los oyentes en el embeleso de sus propias palabras, enmudeciéndolos y alejándolos de la menor controversia. La crítica literaria, el comentario y la valoración de las obras literarias halló en la causerie una de sus formas favoritas. Las otras dos fueron la lectura en voz alta y la recitación de poesía.

Casi podría decirse que en el siglo XIX en Colombia no existía otra forma de la lectura que la lectura en voz alta. El artículo 42 del decreto 1.238 de 1892 que se ocupaba del Colegio del Rosario, establecía que en la institución se enseñaran, además de latín, francés e inglés, ortografia, ortología, lexicografía, sintaxis y, por supuesto, lectura mecánica, ideológica y estética, tanto en prosa como en verso (Gallego Cardona 35). Como explicaba una guía de la época, publicada por la Secretaría de Instrucción Pública en la revista $E l$ Maestro de Escuela, la lectura mecánica era "el arte de leer con claridad, fuerza de voz y

\footnotetext{
${ }^{8}$ Sobre la conversación puede consultarse mi artículo "El arte de la causerie en la Atenas suramericana".
} 
calma que conviene para hacerse oír perfectamente"(Blume y Serrano 163). Se suponía que el estudiante, al ingresar al colegio, ya había asistido por algunos años a la escuela elemental, y que en el colegio comenzaría por mejorar las condiciones de la lectura en voz alta y a despojarse del sonsonete, ese gran vicio que le había dejado el aprendizaje de las primeras letras. Las condiciones de la lectura mecánica eran las siguientes:

$1^{\text {a }}$ Fuerza de la voz;

$2^{\mathrm{a}}$ Pureza en la pronunciación;

$3^{\mathrm{a}}$ Leer de corrida sin embarazo alguno, y

$4^{\mathrm{a}}$ La debida entonación y separación de palabras y de ideas (Blume y Serrano 164). ${ }^{9}$

El segundo nivel en el aprendizaje de la lectura se llamaba "lectura ideológica" y consistía en "el hábito de leer dándose cuenta intelectual de las ideas contenidas en la composición"; sus condiciones eran:

$1^{a}$ Conocimiento de la significación filológica y científica de cada palabra;

$2^{\mathrm{a}}$ Conocimiento de la estructura gramatical de cada frase y de cada oración;

$3^{\text {a }}$ Conocimiento del género literario a que pertenece la composición, y

$4^{\mathrm{a}}$ Discernimiento y buen criterio para distinguir las bellezas y los errores de cualquier especie que contenga la misma composición (Blume y Serrano 165).

El último nivel correspondía a la "lectura estética" y se definía como "el arte de leer con la entonación que exijan los sentimientos de cualquier género que vayan envueltos en la idea de la composición" (166). En este nivel no había más condición que la de que el maestro leyera bien y sirviera de modelo a sus estudiantes; se recomendaban, además, ejercicios de recitación.

El tratado más importante de la lectura en voz alta también era francés: L'art de la lecture (1878) de Ernst Legouvé, obra que alcanzó numerosas ediciones en poco tiempo y que reposaba en la biblioteca de Miguel Antonio Caro. ${ }^{10}$ L'art de la lecture iba dirigido a

\footnotetext{
${ }^{9}$ Los métodos para la enseñanza de la lectura tienen su propia historia. El método del deletreo, muy difundido hasta el siglo XIX, consistía en que el estudiante al ver una palabra como "trabajo", dijera "Te, ere, a, tra; be, a, ba; jota, o, jo: tra-ba-jo"; el silabeo intentaba subsanar las desventajas del deletreo (no había lógica alguna en pedir que el estudiante dijera, por ejemplo, "jota, o, jo") pero no lograba librar a los estudiantes del sonsonete. De aquí que la "lectura mecánica" tuviera como metas las de "leer de corrida sin embarazo alguno, y (...) la debida entonación y separación de palabras y de ideas". Para una historia de los métodos de enseñanza de la lectura véanse Tranck de Estrada y Torre Revello. ${ }^{10}$ Caro poseía la $18^{\mathrm{a}}$ edición. Nosotros citamos de la $37^{\mathrm{a}}$ (Paris: Bibliothèque d'éducation et de récréation, 1897). En lengua castellana pueden mencionarse tratados como el de Juan de la Cuesta, Libro y tratado para ensenar leer y escriuir breuemente y con facilidad co[n] reta [recta] pronunciacion y verdadera ortographia todo romance castellano: $y$ de la distincion y diferencia que ay en las letras consona [n] tes de vna a otras en su sonido y pronunciacion (1589).Entre los manuales que se publicaron en lengua inglesa pueden mencionarse Thomas Sheridan, Lectures on the Art of Reading (1775), Bilbad Barney, An Introduction to the Art of Reading (1796), Daniel Staniford, The Art of Reading (1813), John Hanbury Dwyer, An Essay on Elocution (1843), Alexander Melville Bell, The Art of Reading (1845), S.S. Hamill, The Science of Elocution (1878), James Sheridan Knowles, The Elocutionist (27 ed., 1883), Samuel Hasluck, The Elements of Elocution (1886), etc.
} 
los estudiantes de la escuela secundaria y a sus instructores; sus explicaciones eran sencillas y venían acompañadas de anécdotas y recuerdos del autor. Para Legouvé el arte de la lectura se componía de dos aspectos fundamentales: la voz y el pensamiento; la calidad de la voz dependía de la respiración, la articulación, la puntuación y la pronunciación; del pensamiento no decía gran cosa, salvo que un dominio exhaustivo de la voz no bastaba para comunicarlo. Para ilustrar la manera perfecta en que se debía leer poesía, Legouvé recordaba unas palabras de su maestro, Monsieur Febvé:

Je commencerai par faire le tour de l'assemblée avec le regard; ce regard circulaire et accompagné d'un demi-sourire légèrement esquissé sur les lèvres, doit être agréable, aimable; il a pour objet de récolter pour ainsi dire comme dans une quête les premières sympathies de l'assemblée, et de ramener sur vous tous les jeux; alors, on fait un petit appel de gosier ... hum! hum! Comme si on allait commencer ... on ne commence pas encore! Non! On attend que le silence soit bien complet ... puis on avance le bras ... le bras droit ... en arrondissant gracieusement le coude ... le coude est l'âme du bras! l'attention redouble, vous dites le titre. Vous le dites simplement, sans effet, vous jouez le rôle d'une affiche, le Chêne et le Roseau. Vous commencez: le Chêne; ici, la voix large! Le son étoffé! ... le geste noble et quelque peu emphatique! (116).

Empiezo por recorrer con la vista la sala; la mirada, dirigida a todo el auditorio y acompañada de una leve sonrisa, debe comunicar agrado; el propósito es obtener por adelantado el apoyo y la simpatía del público y ganar su atención. Entonces hago un pequeño sonido con la garganta - ¡ iejem! ¡jejem! - como si hubiera llegado el momento de comenzar. En realidad no, no todavía. No. Espero hasta que se haya hecho perfecto silencio. Luego extiendo el brazo, el derecho, doblando el codo delicadamente -el codo es el alma del brazo ... Ahora sí el interés y la atención están en su punto, y yo doy el título. Lo digo de una manera sencilla, sin pretender ningún efecto, como si fuera simplemente un anuncio: El roble y el rosal. Y entonces sí comienzo: 'El roble', digo con una voz plena y rotunda, y con un gesto amplio y un tanto enfático (Traducción mía).

Ahora bien, cuando al leer, Monsieur Febvé movía el codo, "el alma del brazo", empleaba una mímica que acercaba la lectura en voz alta a la misma recitación; y la recitación era un ejercicio fundamental para mejorar la lectura en voz alta. En realidad, casi no había texto escolar de la época que no trajera referencias a la recitación, ni maestro que no exigiera de sus discípulos un poema de memoria, ni párvulos amedrentados que no pasaran al frente del salón de clase para decir algunos versos dedicados a Dios, a la Naturaleza o a la Patria.

Ciertamente, la historia de la poesía colombiana del siglo XIX es inconcebible sin el brillo que le prestan sus recitadores. La recitación determinaba el éxito de un poema, era su prueba de fuego. Con la recitación, pensaban, la poesía adquiría su dimensión más pura; se hacía carne, gesto, sentimiento a flor de piel que envolvía con su abrazo al poeta, al recitador y al público. El momento de gloria de un poema como "La luna", de Diego Fallon, no se presenta sino cuando Ricardo Carrasquilla lo lee en voz alta a los contertulios de $E l$ Mosaico, y más aún, cuando José María Rojas Garrido lo recita sobre las mesas de La Botella de Oro. 
El más grande recitador de la segunda mitad del siglo XIX en Colombia fue José Joaquín Ortiz, y su fama sólo llegó a ser superada, con el cambio de siglo, por Guillermo Valencia. La estrofa predilecta de Ortiz fue la silva, cuya extensión y libre combinación de heptasílabos y endecasílabos le permitía abundar en imágenes visuales, en apóstrofes al auditorio y en efectos sonoros como la aliteración, la enumeración, la exclamación y la repetición. Su misma fisonomía, en la descripción que de él hace Rafael María Carrasquilla, favorecía el efecto de sus recitaciones: el brillo de los ojos, la amplitud de la frente, la blancura de los cabellos indomables y mal peinados hacia atrás, la voz intensa, "alta, conmovedora, solemne" y capaz de dominar con facilidad "el murmullo de entusiasmo del público" (50). En fiestas patrias como la del 20 de julio, subía Ortiz a la tribuna para recitar poemas dedicados a Bolívar o a Colombia. El más conocido de esos poemas fue "La bandera colombiana":

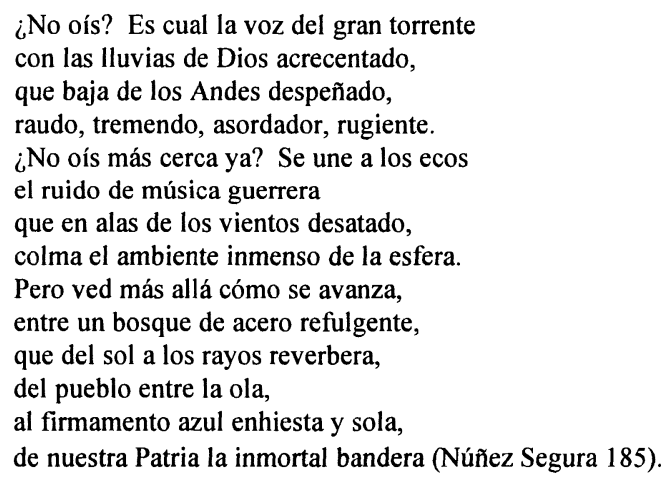

Una estética contemporánea podría juzgar de mediocres estos versos y condenar sus lugares comunes ("alas de los vientos", "aceros refulgentes") o sus ripios ("asordador, rugiente", "firmamento azul"), pero desde el punto de vista de la recitación y de la ocasión en que se recitaba, se trata de una composición casi perfecta; para que los pronuncie la voz de Ortiz, abundan en ella las aliteraciones ("ruido de música guerrera") y los sonidos vibrantes y oclusivos (torrente, acrecentado, despeñado, rugiente); para que lo realcen sus gestos, hay continuas apelaciones al público (“¿no oís?”, “¿no oís más cerca ya?”) e imágenes visuales ("ved más allá ... enhiesta y sola ... la inmortal bandera"). El crítico José A. Núñez Segura no se equivoca al señalar que en el poema la idea "se diluye a veces hasta perderse en exceso de palabras", o que "el desarrollo tiene en ocasiones más fuerza oratoria que poética", pero era precisamente de eso de lo que se trataba (188).

A Ortiz se debe, además, "Lectura y recitación", uno de los primeros tratados de recitación que se escribieron en Colombia y que Ortiz incluyó como apéndice en sus Lecturas selectas en prosa y verso para los alumnos de las escuelas de Colombia (1880). Le siguieron otros tratados y textos escolares, todos ellos más bien influidos por la obra del español José Gómez Hermosilla, Arte de hablar bien en prosa y verso (1826). Comparado con todos ellos, el tratado de Ortiz es muy superior en erudición, en precisión y en abundancia de recomendaciones específicas. 
Las fuentes de Ortiz son autores clásicos como Cicerón y Quintiliano, pero también se sirve de los tratados de Luis de Granada, Blaise Gisbert, Hugh Blair y Julián Romea. Siguiendo a Quintiliano, divide su estudio en dos partes: la voz y el gesto. Respecto de la voz, dice, se han de tener en cuenta tres aspectos: en primer lugar, la pronunciación, que debe ser clara; en segundo lugar, la cantidad de la voz, es decir, la intensidad y el tono, que puede ser, a su vez, alto, medio y grave; y por último, la variedad, es decir, "las modulaciones variadas de una voz ya elevada, ya suave, ya lenta o precipitada, que marcan la diferencia de sentimientos que se quiere expresar o excitar" (310). En cuanto al gesto, pide Ortiz que el cuerpo se mantenga "erecto y firme", que la cabeza siga "la dirección de las manos y la oscilación del cuerpo", y que el rostro, y sobre todo la mirada, refleje el sentimiento que se expresa (310 ss.). A los brazos y a las manos dedica un estudio más extenso y determina para ellos tres tipos de acciones: indicativas, afectivas e imitativas. Cada una de estas acciones se desarrolla de acuerdo con reglas muy precisas. Para las acciones indicativas, por ejemplo, Ortiz establece un complejo juego de relaciones entre la mirada y los brazos, de manera pues, que para señalar la altura "se bajarán los brazos, al mismo tiempo que los ojos se elevarán hacia el vértice imaginario del objeto de que se habla", y para señalar la profundidad, "se levantarán desigualmente ambos brazos, mientras que la mirada, fija en el suelo, parecerá medir la profundidad del abismo" (315). En el caso de las acciones afectivas, el principio general es el crescendo, esto es, la idea de que "[Las] acciones deben desarrollarse y multiplicarse más, a medida que los sentimientos son más vivos y sea más animado el discurso"; si se trata de un sentimiento íntimo, "se puede llevar al pecho la mano derecha"; si se trata de una expresión de autoridad, "se extiende el brazo a la altura del hombro, volviendo la palma de la mano hacia la tierra, con el índice extendido, y bajándolo un poco como si se apoyase en alguna cosa" (316). Finalmente, para las acciones imitativas se impone el deber de conservar el decoro y de evitar la "mímica ridícula e inconveniente" (317).

Cuando se considera que en el siglo XIX el medio de difusión más importante de la poesía fue la recitación, no es aventurado suponer que las indicaciones de Ortiz operaran como una suerte de ars poetica y determinaran la misma forma de componer versos; en efecto, el éxito de un poema residía en gran parte en la ocasión que ofrecía al recitador para exhibir su arte, en las oportunidades que presentaba para introducir un gesto más vivo o un tono de voz más intenso. Un sistema físico y operático, una economía de la voz y el cuerpo acompañaba a las palabras y, en consecuencia, se prefería la composición extensa a la breve y la secuencia narrativa a la imagen instantánea; si había en ella la evolución de un sentimiento era para que lo marcara la voz; y si había una acción mimética era para que la dibujaran las manos en el aire.

Uno de los primeros best-sellers de la literatura colombiana fue $\operatorname{Pax}$ (1907), novela en clave que agotó dos ediciones en poco tiempo, fue traducida al inglés y mereció un estudio acervo de Marco Fidel Suárez titulado Análisis gramatical de 'Pax' (1907). La novela, ahora olvidada, fue escrita por Lorenzo Marroquín y José María Rivas Groot, y en ella se hacía un retrato satírico de la política y de la alta sociedad colombianas. Entre sus personajes había un poeta, S. C. Mata ("Ése se mata"), que era una burla de José Asunción Silva. Una vez llega Mata a una recepción y de inmediato lo rodean los asistentes y le piden que recite: 
— ¡Sí .... sí dijeron varios; que hable.

- Se lo suplico, bardo amigo.

- La balada de la desesperanza.

- Metamorfosis.

- Sinfonia en gris mayor.

- Nostalgia egipcia.

- ¡Sí, sí, eso! Nostalgia egipcia.

Condujeron al poeta a un ángulo del salón, se sentaron las parejas y empezó Mata su recitación. Los espejos colosales copiaban la escena: las señoras ocultaban el fastidio detrás de los abanicos; algunas muchachas cuchicheaban con sus novios; otras, acreditándose de literatas, alargaban el cuello, prestando grande atención; los hombres, en pie, en un círculo apretado, ostentaban las banderitas en el ojal, cintajos blancos, y mostraban sus fisonomías aburridas, en tanto que el poeta junto al balcón, en plena luz, caídos los párpados que dejaban ver la línea roja de una pupila sanguinolenta, alzaba y bajaba los brazos, iba y venía como un hombre que se bambolea en una barca (I: 224).

La recitación de Mata era precisamente lo que el arte de la recitación no era o no debía ser. Como sugería Monsieur Febvé a propósito de la lectura en voz alta, los ojos del recitador, sus gestos y su voz enfática debían atraer sobre sí toda la atención del auditorio. Lo contrario era fracasar. En el arte de la recitación no había lugar a divergencias. En el viento que levantaban las palabras del recitador debía desaparecer todo lo anodino, los abanicos de las damas, los cuchicheos de los jóvenes, el tedio de los caballeros. Nada más podía existir en ese instante como no fueran las palabras del recitador y los gestos en que apoyaba sus palabras. Cuando concluyera, cuando una salva de aplausos lo obligara a inclinarse en una venia ante su público, bien pudiera ser que regresaran las pequeñas cosas, los abanicos, los espejos, las banderitas en el ojal, las conversaciones dispersas, las distintas animaciones de la reunión, pero sin excepción, movidos por un mismo sentimiento de solidaridad, los circunstantes declararían haber vivido entonces un momento poético, sublime, solemne, inolvidable. Por otra parte, ¿quién que tuviese un poco de razón se hubiese atrevido a opinar lo contrario? Si por crítica literaria se entendía la valoración de una obra literaria, no cabe duda de que esa valoración se realizaba en el medio hegemónico, casi monolítico, de la vida intelectual privada, esto es, de la conversación bien llevada y sin penosas discrepancias, de la recitación embelesada y de la lectura en voz alta. Si comportaba además un delicado discernimiento, un manoseo de las ideas, como definía Sanín Cano la vida intelectual pública, debe admitirse que la crítica literaria se alimentaba también de la discordia aunque soterrada y animada por artículos anónimos o firmados con seudónimos como "Academo", "Macabeo" o "Ateniense". Tal, pues, la atmósfera idílica y opresiva a un tiempo en la que por muchos años se discutió de ideas y de libros en "la ciudad del águila negra".

\section{Obras citadas}

Academo. "Ateneo de Bogotá". El Correo Nacional (19 agosto 1891): 3.

Arciniegas, Ismael Enrique. Paliques. Vol. I. Bogotá: ABC, 1938. 
Biblioteca Nacional de Colombia. Catálogo de publicaciones seriadas siglo XIX. Bogotá: Biblioteca Nacional de Colombia; Instituto Colombiano de Cultura, 1995. 2 Vols.

Blume, Alberto y Nepomuceno Serrano. "Organización de las escuelas públicas de

Bogotá”. El Maestro de Escuela I/6 (20 mayo 1899): 161-90.

Cané, Miguel. Notas de viaje sobre Venezuela y Colombia. 1882. Bogotá: Luz, 1907.

Carrasquilla, Francisco de Paula. Tipos de Bogotá. Bogotá, 1886.

Carrasquilla, Rafael María. "D. José Joaquín Ortiz". Papel Periódico Ilustrado 2.28 (1 de octubre de 1882): 50-55. Edición facsimilar. Cali: Carvajal, 1975.

Casas, José Joaquín. “Diego Fallon”. 1915. Colombianos ilustres. Rafael María Mesa Ortiz, ed. Bogotá: La República, 1916. I: 173-225.

Fayad, Luis. Los parientes de Ester. 1979. Bogotá: Oveja Negra, 1984.

Gallego Cardona, Juan. Pénsumes colombianos de enseñanza secundaria, 1887-1955. Medellín: Imprenta Departamental de Antioquia, 1955.

García Ortiz, Laureano. Conversando.... Bogotá: Minerva, 1925.

Gilbert, Alan. "Bogotá: Politics, Planning, and the Crisis of Lost Opportunities". Metropolitan Latin America: The Challenge and the Response. Wayne A. Cornelius y Robert V. Kemper, eds. Beverly Hills: Sage Publications, 1978. 87-126. Vol. 6 de Latin American Urban Research.

Helg, Aline. La educación en Colombia, 1918-1957: Una historia social, económica y política. 1984. Bogotá: Cerec, 1987.

Jaramillo-Zuluaga, J. Eduardo. "El arte de la causerie en la Atenas suramericana". El Malpensante 1.3 (marzo 1997): 80-5.

Legouvé, Ernst. L'art de la lecture. París: Bibliothèque d'éducation et de récréation, 1897.

Mora, Luis María. "Don Luis María Mora". Los contertulios de la Gruta Simbólica. Bogotá: Ministerio de Educación Nacional, 1936. 5-27.

Marroquín, Lorenzo y José María Rivas Groot. Pax. 1907. Bogotá: Ministerio de Educación Nacional, 1946. 2 Vols.

"Nota bibliográfica sobre doña Soledad Acosta de Samper". Revista del Colegio Mayor de Nuestra Señora del Rosario V/47 (1 de agosto de 1909): 446.

Núñez Segura, José A., Literatura colombiana. 1952. Medellín: Bedout, 1964.

Ortiz, José Joaquín. "Lectura y recitación". Lecturas selectas en prosa y verso para los alumnos de las escuelas de Colombia. Bogotá: Imprenta de Medardo Rivas, 1880. 299-318.

Palacios, Marco. "La clase más ruidosa: a propósito de los reportes británicos sobre el siglo XX colombiano". Eco 254 (diciembre 1982): 113-56. Reproducido en Estado y clases sociales en Colombia. Bogotá: Procultura, 1986. 9-86.

Rama, Ángel. La ciudad letrada. Hannover: Ediciones del Norte, 1984.

Reclús, Eliseo. Colombia. Trad. F. J. Vergara y Velasco. Bogotá: Biblioteca Schering Corporation USA, 1965.

Samper, José María. Historia de un alma, de 1834 a 1881. 1881. Vol. I. Bogotá: Ministerio de Educación Nacional, 1946.

[Sanín Cano, Baldomero]. "Entre académicos". El Telegrama (28 de agosto de 1891): 5752. 
Enrique Santos Molano. El corazón del poeta. Los sucesos reveladores de la vida y la verdad inesperada de la muerte de José Asunción Silva. Bogotá: Nuevo Rumbo, 1992.

Torre Revello, José. "Las cartillas para enseñar a leer a los niños en América española". Boletín del Instituto Caro y Cuervo 15 (1960): 214-34.

Tranck de Estrada, Dorothy. "La enseñanza de la lectura y de la escritura en la Nueva España, 1700-1821". Historia de la lectura en México. Pilar Gonzalbo A., et al. México: Colegio de México, 1988. 49-93.

Villa, Hernando. "Recuerdos de Silva". 1946. Leyendo a Silva. Vol. I. Juan Gustavo Cobo Borda, ed. Santafé de Bogotá: Caro y Cuervo, 1994. 375-80. 
